\title{
Epstein-Barr virus in pleural effusions: protagonist or pretender?
}

\author{
To the Editor:
}

Unilateral pleural effusions are a common diagnostic challenge for the respiratory physician. In the majority of patients, a diagnosis can be made according to medical history, computed tomography and pleural fluid analysis [1]. A proportion of patients will require a pleural biopsy but, following this, a minority will remain undiagnosed and are defined as having inflammatory pleuritis (IP) [2]. These patients often require extended follow-up to ensure effusion resolution and exclude malignancy.

A previous prospective study proposed a possible causative role of the Epstein-Barr virus (EBV) in "unexplained" pleural effusions, after finding that nearly $60 \%$ had evidence of EBV DNA within the pleural fluid [3]. This hypothesis has not been validated in an external cohort. Our aim was to determine the presence and quantity of EBV in the pleural fluid and serum of patients with "undiagnosed" pleural effusions compared to controls.

Patients presenting with undiagnosed pleural effusions were prospectively recruited to this single-centre UK-based observational study and consented to having serum and pleural fluid stored. All were assigned a 12-month diagnosis as to the most likely cause of their effusion. The final diagnosis was agreed by two independent respiratory consultants. A diagnosis of IP required histocytological evidence (biopsy negative for malignancy), in the absence of markers of infection (significantly raised white blood cells or C-reactive protein) or a known history of asbestos exposure (to exclude cases of parapneumonic effusion or benign asbestos-related pleural effusions, respectively). The full diagnostic criteria used in the study have been previously published [4]. Patients with final diagnosis of IP had pleural fluid and serum analysed for the presence of EBV. A selection of controls, matched by presentation date, of transudative effusions (cardiac, liver or renal failure) and parapneumonic effusions were also analysed.

Samples were stored at $-70^{\circ} \mathrm{C}$ and analysed en bloc. Nucleic acids were extracted from pleural fluid and serum using the Qiagen DSP virus/pathogen extraction kit according to the manufacturer's instructions (Qiagen, Dusseldorf, Germany). In-house real-time PCR was performed (in duplicate) using nucleic acid extracts spiked with T4 phage as internal control, TaqMan Fast Universal PCR Master Mix (Isogen Biosciences, Maarssen, the Netherlands), and in-house EBV primers [5]. EBV DNA levels were estimated from the cycle threshold $\left(\mathrm{C}_{t}\right.$ value) at which DNA amplification became detectable (the limit of detection is about is approximately 1000 copies $\left.\cdot \mathrm{mL}^{-1}\right)$.

EBV serology was performed using the LIAISON XL platform (DiaSorin, Saluggia, Italy), testing for anti-EBV antibodies using the EBV IgM, VCA IgG (EBV capsid antigen) and EBNA IgG (EBV nuclear antigen) reagents.

Continuous data are expressed as medians (with ranges) and compared using a Mann-Whitney U-test. Noncontinuous data were analysed using Fisher's exact test. $\mathrm{p}<0.05$ was used to define significance.

Between 2008 and 2017, 1005 consecutive patients with a new pleural effusion were enrolled and had a 12-month diagnosis. IP was diagnosed in 27 cases (3\%). The median age was 70 years (range 53-92 years) and there was a male predominance (23 out of $27,85 \%)$ (table 1 ). The presence of EBV was assessed in these and 163 controls (54 transudates, 109 parapneumonic effusions). EBV DNA was found in the pleural fluid of $14.8 \%$ (four out of 27) of IP cases compared to $13.8 \%$ (15 out of 109) of parapneumonic and 5.6\% (three out of 54) of transudative effusions. $C_{t}$ values across all groups were high, ranging from 33.8 to 41.2, indicating the presence of low levels of EBV DNA. There was no significant difference in pleural fluid

@ERSpublications

Previous studies have suggested an association between Epstein-Barr virus (EBV) and inflammatory pleuritis (IP). The incidence of IP in this 1005-patient cohort was 3\%, with no evidence of increased pleural fluid EBV DNA compared to controls. http://bit.ly/2lVGvNV

Cite this article as: Arnold DT, Suri T, Hamilton F, et al. Epstein-Barr virus in pleural effusions: protagonist or pretender? Eur Respir J 2019; 54: 1900825 [https://doi.org/10.1183/13993003.00825-2019]. 


\begin{tabular}{|c|c|c|c|}
\hline & Inflammatory pleuritis & Parapneumonic & Transudates \\
\hline Patients & 27 & 109 & 54 \\
\hline Age years & $68(53-92)$ & $63(18-95)$ & 78 (55-97) \\
\hline Male/female & $23 / 4$ & $70 / 39$ & $32 / 22$ \\
\hline Duration of symptoms months & $3(0.2-12)$ & $0.2(0.1-3)$ & $4(0.1-24)$ \\
\hline \multicolumn{4}{|l|}{ Laterality } \\
\hline Right & 18 & 57 & 31 \\
\hline Left & 7 & 44 & 6 \\
\hline Bilateral & 2 & 8 & 17 \\
\hline $\mathrm{CRP}^{\#} \mathrm{mg} \cdot \mathrm{L}^{-1}$ & $17(1-70)$ & $145(8-429)$ & $24(1-75)$ \\
\hline \multicolumn{4}{|l|}{ Pleural fluid analysis ${ }^{\pi}$} \\
\hline Lymphocytic & $14(52)$ & $18(17)$ & $22(41)$ \\
\hline Neutrophilic & $0(0)$ & $58(53)$ & $0(0)$ \\
\hline Eosinophilic & $6(22)$ & $8(7)$ & $4(7)$ \\
\hline Mixed & $7(26)$ & $25(23)$ & $28(52)$ \\
\hline Pleural fluid protein ${ }^{\#} g \cdot L^{-1}$ & $44(24-59)$ & $43(17-68)$ & $23(12-31)$ \\
\hline Presence of pleural fluid EBV DNA & $4(14.8)$ & $15(13.8)$ & $3(5.6)$ \\
\hline $\mathrm{C}_{\mathrm{t}}^{+}$ & $36.5(34.5-38.9)$ & $36.8(33.8-41.1)$ & $37.2(36.0-37.8)$ \\
\hline \multicolumn{4}{|c|}{$\begin{array}{l}\text { Data are presented as } \mathrm{n} \text {, median (range) or } \mathrm{n}(\%) \text {, unless otherwise stated. CRP: C-reactive protein; EBV: } \\
\text { Epstein-Barr virus; } \mathrm{C}_{\mathrm{t}} \text { : cycle threshold. "\#: mean (range); ": cell differential definitions were lymphocytic } \\
\text { effusion }>50 \% \text {, neutrophilic }>50 \% \text {, eosinophilic }>10 \%, ~ " \text { mixed" means no predominant cell type; ": when } \\
\text { pleural fluid EBV detected. }\end{array}$} \\
\hline
\end{tabular}

EBV levels depending on effusion aetiology or predominant cell types ( $p=0.183$ and $p=0.248$ respectively, using the Mann-Whitney U-test). The analysis was repeated using the qualitative EBV PCR results, with no relationship found between the same groups ( $\mathrm{p}=0.354$ and $\mathrm{p}=0.701$ respectively, using Fisher's exact test). Serological testing and serum EBV PCR were performed for cases where pleural fluid EBV DNA was detected. All cases showed evidence of past EBV infection; none had detectable EBV IgM. On PCR, EBV DNA was found in low levels in the serum of five cases, all of whom had a final diagnosis of parapneumonic effusion.

This study did not find evidence of EBV as a causative factor in the development of IP. A previous cohort study published by THIJSEN et al. [3] in the European Respiratory Journal found EBV DNA in the pleural fluid of $40 \%$ of a 60 -patient cohort with all-cause effusions. The prevalence of positive pleural fluid EBV DNA was higher in the 34 patients with "unexplained" pleural effusions. This prompted the authors to suggest that EBV reactivation might have a causative role in their development. This current study attempted to validate these findings using a 190-patient cohort in whom IP was only diagnosed after a biopsy and 12 months of radiological follow-up.

EBV or human herpesvirus 4 infections are very common and by adulthood around $90 \%$ of individuals have been infected [6]. Acute infection is usually asymptomatic in the immunocompetent or can manifest itself as infectious mononucleosis. Following the acute phase, B-lymphocytes become latently infected and EBV can persist with low/intermittent virion production. Reactivation within the lung can occur, usually resulting from immunosuppression. A series of 20 cases of EBV-DNA-positive pleural effusions was published by TAKEI and MODY [7]. All cases had a history of lung transplantation but EBV loads were relatively low.

EBV as a possible causative agent in pleural effusions is a plausible concept for a number of reasons. First, some effusions will remain undiagnosed despite conventional histocytological investigations. Secondly, those presenting with pleural effusions might be immunocompromised due to age and/or immunosuppressive medications. Finally, the course of exudative effusions can be relapsing and remitting, suggesting a reactivating viral process.

We examined a cohort of patients in whom the diagnosis was elusive despite pleural fluid analysis, imaging follow-up and histological biopsy. These patients were termed as having IP (literature terms include idiopathic, inflammatory, nonspecific or fibrous pleuritis) and require fastidious follow-up to exclude malignancy. Previous retrospective studies have found that $12-18 \%$ of cases of IP at initial biopsy have an underlying malignant cause [8,9]. Identifying the other causes would be extremely useful for risk stratification. In this study, patients were diagnosed with IP after at least 1 year of follow-up, no known 
history of asbestos exposure (to exclude benign asbestos pleural effusions), and a nondiagnostic pleural biopsy result. All cases were stable or resolved at 1 year and are therefore truly idiopathic.

In $15 \%$ of the IP cases, EBV was present within pleural fluid but only at very low levels. This prevalence was not significantly different to the infected or transudative controls. Additionally, there was no serological evidence of recent or reactivated EBV in cases with pleural fluid positive for EBV. We hypothesise that the low levels of EBV DNA found in these pleural fluid samples may be a result of latently infected B-lymphocytes without a pathological role.

In conclusion, we found no evidence that EBV was a causative factor in cases of IP and testing for EBV in these cases is unlikely to be diagnostic.

David T. Arnold ${ }^{1}$, Tim Suri ${ }^{2}$, Fergus Hamilton ${ }^{3}$, Anna Morley ${ }^{1}$, Andrew Medford ${ }^{1}$, Ian B. Vipond ${ }^{4}$, Peter Muir $\oplus^{4}$ and Nick A. Maskell ${ }^{1}$

${ }^{1}$ Academic Respiratory Unit, School of Translational Health Sciences, University of Bristol, Bristol, UK. ${ }^{2}$ School of Cellular and Molecular Medicine, University of Bristol, Bristol, UK. ${ }^{3}$ Dept of Microbiology, North Bristol NHS Trust, Bristol, UK. ${ }^{4}$ Public Health England, South West Regional Laboratory, National Infection Service, Bristol, UK.

Correspondence: David T. Arnold, Level 2, Learning and Research Building, Southmead Hospital, Bristol, BS10 5NB, UK. E-mail: arnold.dta@gmail.com

Received: 26 April 2019 | Accepted after revision: 12 June 2019

Conflict of interest: None declared.

\section{References}

1 Hooper C, Lee YC, Maskell N, et al. Investigation of a unilateral pleural effusion in adults: British Thoracic Society Pleural Disease Guideline 2010. Thorax 2010; 65: Suppl. 2, ii4-ii17.

2 Venekamp LN, Velkeniers B, Noppen M. Does "idiopathic pleuritis" exist? Natural history of non-specific pleuritis diagnosed after thoracoscopy. Respiration 2005; 72: 74-78.

3 Thijsen SF, Luderer R, van Gorp JM, et al. A possible role for Epstein-Barr virus in the pathogenesis of pleural effusion. Eur Respir J 2005; 26: 662-666.

4 Arnold DT, De Fonseka D, Perry S, et al. Investigating unilateral pleural effusions: the role of cytology. Eur Respir J 2018; 52: 1801254.

5 Niesters HG, van Esser J, Fries E, et al. Development of a real-time quantitative assay for detection of Epstein-Barr virus. J Clin Microbiol 2000; 38: 712-715.

6 Cohen JI. Epstein-Barr virus infection. N Engl J Med 2000; 343: 481-492.

7 Takei H, Mody D. Epstein-Barr virus-positive pleural effusion: clinical features, cytomorphologic characteristics, and flow cytometric immunophenotyping. Am J Clin Pathol 2014; 142: 788-794.

8 Davies HE, Nicholson JE, Rahman NM, et al. Outcome of patients with nonspecific pleuritis/fibrosis on thoracoscopic pleural biopsies. Eur J Cardiothorac Surg 2010; 38: 472-477.

9 Metintas M, Ak G, Cadirci O, et al. Outcome of patients diagnosed with fibrinous pleuritis after medical thoracoscopy. Respir Med 2012; 106: 1177-1183. 